\title{
Capture and blood sampling do not affect foraging behaviour, breeding success and return rate of a large seabird: the black-browed albatross
}

\author{
Frédéric Angelier · Henri Weimerskirch • \\ Olivier Chastel
}

Received: 12 March 2010/Revised: 29 July 2010/Accepted: 21 September 2010/Published online: 2 October 2010

(C) The Author(s) 2010. This article is published with open access at Springerlink.com

\begin{abstract}
During the last decades, eco-physiological studies have usually relied on the collection of blood from wild organisms in order to obtain relevant physiological measures. However, accurate estimates of the impact of capture and blood collection on performances of Polar seabird species have rarely been conducted. We investigated for the first time the effects of a blood sampling process on subsequent foraging behaviour, reproductive performance and return rate of black-browed albatrosses (Thalassarche melanophris) at Kerguelen Islands. We did not find any evidence that the blood sampling process as conducted in our study had detrimental effects on the breeding or foraging strategies or performance of blackbrowed albatrosses. Because blood collection can be performed in several different ways, we recommend that eco-physiologists conduct pilot studies to test whether their blood sampling process affects the performances of their study species.
\end{abstract}

Keywords Albatross - Disturbance - Blood sample . Handling · Survival · Foraging

\section{Introduction}

During the last decade, physiological measurements have been increasingly used to provide insights into

F. Angelier · H. Weimerskirch · O. Chastel Centre d'Etudes Biologiques de Chizé, CNRS,

79360 Villiers en Bois, France

F. Angelier $(\square)$

Department of Neurobiology, Physiology and Behaviour,

University of California, Davis, CA 95616, USA

e-mail: fangelier@ucdavis.edu evolutionary and ecological questions (Zera and Harshman 2001; Ricklefs and Wikelski 2002; Wingfield et al. 2008; Angelier and Chastel 2009). These interdisciplinary approaches usually require the collection of tissues from wild organisms in order to obtain physiological measures. In this respect, many eco-physiological studies of vertebrates are based on the collection of blood because it can provide useful information without requiring prolonged restraint, surgery or killing of a wild animal. Thus, immune, metabolic, endocrine, isotopic and toxicological processes in birds are usually studied by performing blood analyses (e.g., Landys et al. 2005; Angelier et al. 2007a; Palacios et al. 2007; Wada et al. 2009). Moreover, red cells are nucleated in birds and can therefore be used for genetic purposes such as sex determination, paternity or ageing processes (e.g., Fridolfsson and Ellegren 1999; Schmoll et al. 2009; Bize et al. 2009). For these reasons, blood sampling is considered an effective and minimally invasive technique to collect physiological measurements in wild birds (Gaunt et al. 1997; Sheldon et al. 2008).

Field eco-physiologists, like ecologists and managers, have acknowledged that blood sampling may be detrimental to free-living birds (Oring et al. 1988; Gaunt et al. 1997; Sheldon et al. 2008). First, it requires capturing and restraining the birds for several minutes, which may be stressful to the individual. Second, blood collection may induce injuries or haematomas and weaken a bird if the volume of withdrawn blood is too large (Gaunt et al. 1997). As a consequence, the blood sampling process can potentially induce detrimental effects on the reproductive performance and survival of sampled birds. For instance, the blood sampling process can result in nest desertion (Colwell et al. 1988; Kania 1992; Criscuolo 2001) or even mortality in some species (Brown and Brown 2009). Many studies have investigated the effects of the blood sampling 
process on terrestrial bird performances (Wingfield and Farner 1976; Dufty 1988; Hoysak and Weatherhead 1991; Lanctot 1994; Lubjuhn et al. 1998; Perkins et al. 2004; Schmoll et al. 2004; Sheldon et al. 2008), and this has led to the development of guidelines aimed at the ethical collection of blood that minimize the potential deleterious effects on birds (Oring et al. 1988; Gaunt et al. 1997; Sheldon et al. 2008). However and surprisingly, accurate estimates of the impact of blood collection on performances of seabirds have rarely been conducted (Sheldon et al. 2008, but see Brown 1995; Van den Brink and Pigott 1996) despite an increasing number of eco-physiological studies focusing on these species (e.g., Kitaysky et al. 1999; Criscuolo et al. 2002; Hall et al. 2004; Chastel et al. 2005; Cherel et al. 2005; Angelier et al. 2007b, 2010). This is probably the case because seabirds have been considered less susceptible to handling than other birds. However, disturbance is known to substantially increase the heart rate of seabirds, suggesting a high susceptibility to stress (Weimerskirch et al. 2002; de Villiers et al. 2006).

Because seabirds are long-lived birds with a high residual reproductive value, they are predicted to behave as prudent parents and minimize the risk of mortality due to breeding (Drent and Daan 1980). Thus, they should reduce their parental effort in response to a stressor. Consequently, a blood sampling protocol may translate into low reproductive performances and/or modification of their foraging behaviour (a proxy of parental effort, Weimerskirch 1999). Although large seabirds are probably unlikely to die as a consequence of a blood sampling process, they may decide to avoid the area where they were disturbed by refraining from breeding at that location during the following breeding seasons (Blackmer et al. 2004). Therefore, a blood sampling process may induce temporary or permanent emigration and, thus, affect the return rate of seabirds.

In this study, we investigated for the first time the effects of a blood sampling process on the black-browed albatross (Thalassarche melanophris), a long-lived seabird species that is commonly used for eco-physiological studies which make use of blood sampling. To do so, we used an existing data set in which albatrosses were blood sampled for hormone analyses (Angelier et al. 2007a, 2010). Specifically, we examined the combined effects of capture, short restraint and blood sampling on the foraging behaviour (question 1), the reproductive performance (question 2) and the return rate (question 3) of breeding black-browed albatrosses. Age may influence the degree to which birds are affected by a stressor, such as the blood sampling process (Heidinger et al. 2006; Angelier et al. 2007b). Indeed, previous studies have shown that inexperienced albatrosses are less likely to breed successfully and have lower survival rates than experienced birds, especially when conditions are sub-optimal (Pinaud and Weimerskirch 2002; Angelier et al. 2007a). Therefore, we also investigated whether the blood sampling process affected inexperienced breeders more than experienced ones (question 4).

\section{Materials and methods}

Study area and species

We conducted our study on breeding black-browed albatrosses at Cañon des Sourcils Noirs, Kerguelen Islands (Fig. 1; $\left.50^{\circ} \mathrm{S}, 70^{\circ} \mathrm{E}\right)$. Black-browed albatrosses $(3-4 \mathrm{~kg})$ are long-lived birds with a high survival probability (Nevoux et al. 2007; Rolland et al. 2008), a low annual fecundity (one egg per year) and a relatively high breeding success for long-lived seabirds (Pinaud and Weimerskirch 2002; Angelier et al. 2007a). Birds breed annually, although a small proportion of birds skip breeding each year. During the incubating and brooding periods, parents take turns feeding at sea and either incubating their egg or guarding and brooding their offspring. When the chick becomes thermally independent, it is left unattended at the nest and both parents forage at sea to restore their body reserves and feed their chick.

\section{Long-term mark-recapture monitoring}

We used data from an ongoing capture-mark-recapture (CMR) programme of this species initiated on Kerguelen in 1976 (Fig. 1; see Angelier et al. 2007a; Nevoux et al. 2007). Due to this monitoring, pair members can be identified and their breeding performance known (fledging success), allowing us to examine question 2. Moreover, return rate from one breeding season to the next can also be determined by using capture-mark-recapture (CMR) analyses (Rolland et al. 2008), allowing us to examine question 3. Since 1980, every chick at this site has been banded prior to fledging, and their breeding history has been monitored since they returned to the colony to breed for the first time. As a result of this effort, we were able to determine whether a given bird breeding in 2004 had already bred in a previous year (experienced bird) or not (inexperienced bird). In black-browed albatrosses, there is a significant difference in survival and breeding success between inexperienced birds and experienced ones, whereas performances do not increase with further breeding experience among experienced breeders (Angelier et al. 2007a; Nevoux et al. 2007). Therefore, we were able to test whether the influence of a blood sampling process on our variables of interest varies between experienced and inexperienced birds (question 4). A few unbanded albatrosses were found breeding in the colony in 2004, and we were not able to determine with certainty whether they were 
Fig. 1 a Geographical position of the study site; Kerguelen archipelago is circled in red. b View of the colony from the top of the cliff. The study was conducted in the upper part of this black-browed albatross colony. c Picture of a blackbrowed albatross brooding a chick at its nest. All pictures by L. Denonfoux
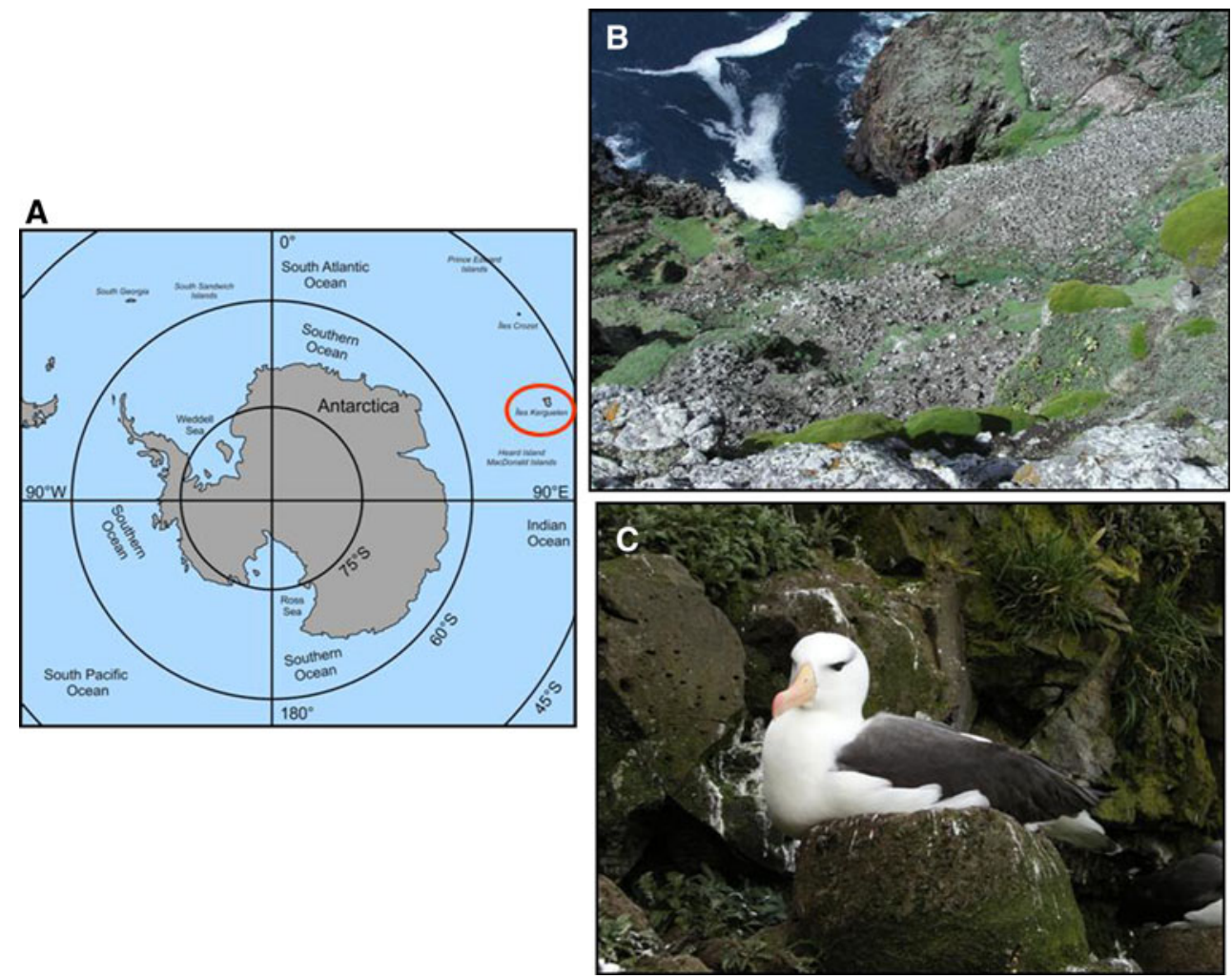

experienced or inexperienced. They were therefore excluded from statistical analyses including 'experience' as a factor.

Capture, blood samples, fledging success and survival

In January 2004, we conducted an eco-physiological study in which 56 parents were captured and blood sampled during the early brooding period (5- to 10-day-old chick, Angelier et al. 2007a) in the upper section of the long-term study colony (hereafter called 'sampled birds'; Fig. 1). The remaining birds in this section of the colony were not captured and sampled (hereafter called 'control birds'). Birds were captured by hand off the nest just after their mate relieved them from brooding duties (i.e., when birds were headed to sea). Blood samples were collected from the tarsus vein with a 1-ml heparinized syringe and a 25-gauge needle. Blood samples never exceeded $0.5 \mathrm{ml}$. Albatrosses were then released near their nests and allowed to depart to sea. Handling time was reduced to the minimum and never exceeded $5 \mathrm{~min}$, and only one bird was captured per nest. Because all the sampled birds were captured, restrained and blood sampled, our protocol cannot help to tease apart whether the capture, the restraint or the blood sampling have different individual effects on birds. However, it allows to understand whether the combination of all these manipulations affects albatrosses.
At the end of the breeding season, each nest of the colony was checked in order to determine fledging success. Thus, we were able to compare fledging success between nests for which one of the parents was captured and blood sampled ( $n=52$, note that fledging success was not monitored for 4 nests) and nests for which no parents were captured and blood sampled ( $n=83$, question 2 ). During the three subsequent seasons, all the nests of the colony were monitored for the long-term CMR programme, and so we were able to determine whether sampled and control birds were seen at the colony in 2006, 2007 or 2008. By using CMR analyses, we were able to estimate whether the probability of returning to the colony differed between 'sampled birds' $(n=56)$ and 'control birds' $(n=200$, question 3).

\section{Behavioural monitoring}

We estimated the time spent foraging at sea of 16 albatrosses breeding in the colony (question 1). Birds were marked with picric acid from a distance (i.e., without handling the bird) with a brush at the beginning of the study period (January 3). The sixteen nests were then regularly monitored from dawn to dusk in order to determine the time spent foraging at sea for each bird (hereafter 'time at sea'). These 16 birds were not disturbed while we 
monitored the duration of their foraging trip (first foraging trip at sea). Immediately before their subsequent foraging trip (second foraging trip at sea), 9 of them were captured and blood sampled as previously described ('sampled birds') and 7 were left undisturbed ('control birds'). All the sampled birds were released near their nests following the procedure, after which we monitored the duration ('time at sea') of the second foraging trip for both sampled and control birds. Therefore, we were able to test whether time at sea differed between sampled birds and controls before and after the sampling process (question 1).

\section{Statistical analyses}

Survival probabilities and breeding frequency of experimental and control birds were estimated and compared with capture-mark-recapture (CMR) models, using the MARK software (White and Burnham 1999). These models include two kinds of parameters: sighting probability and survival probability, allowing us to test for an effect of capture and blood sampling on these two probabilities for albatrosses. In our study, the apparent survival probability $(\Phi)$ represents the probability that an individual survived from 2004 to 2005 and continued to breed in the long-term monitored colony. The probability that an albatross died between 2004 and 2005 or did not return to the colony in the subsequent four years (emigration) is represented by $(1-\Phi)$. The apparent sighting probability $(P)$ represents the probability that an individual bred, but was sighted in the colony in 2005 . The probability that an albatross either bred and was not sighted in the colony in 2005 or did not breed in the colony in 2005 is represented by $(1-P)$. Since the sampled birds and the controls have the same probability to be sighted in the colony when breeding, this apparent sighting probability $(P)$ allows us to determine whether capture and blood sampling affect the probability of black-browed albatrosses to skip breeding in 2005 . Because only a few inexperienced albatrosses were sampled and because survival probability is high in blackbrowed albatrosses (Nevoux et al. 2007), we did not have enough statistical power to test an effect of experience of reproduction on apparent survival and sighting probabilities. Therefore, we did not include this 'experience' factor in this analysis. We started our CMR analysis from the general time-dependent model that states that $\Phi$ and $P$ vary between sampled and control birds and with time. We used a second-order Akaike's Information Criterion (AICc), which corrects for sample size, to select the most parsimonious model (Burnham and Anderson 2002). We calculated this second-order AICc using this formula:

$$
\mathrm{AICc}=-2 \log (\text { Likelihood })+2 K+2 K \frac{(K+1)}{(N-K-1)}
$$

where $N$ is the sample size and $K$ is the number of parameters.

Values for differences in AICc values $(\triangle \mathrm{AICc})$ were computed by subtracting the minimum AICc from all candidate model AICc. Differences between AICc values of different models can be used to determine which model provides the most adequate description of the data on the basis of the fewest model parameters. The model with the lowest AICc is considered the best description of the relationship, given the models compared. $\triangle \mathrm{AICc}$ values $>2$ are a good indicator that the model with the lowest AICc is preferable. $\triangle \mathrm{AICc}$ values $<2$ indicate that models are fairly similar in their ability to describe the data, but the model including the fewest parameters is usually preferable. Moreover, we reported an AICc weight (w), which reflects the relative likelihood of a specific model being the bestfitting model among all the models considered (Burnham and Anderson 2002). We also used likelihood ratio tests (LRT) to test two specific biological hypotheses: (1) $P$ differed between sampled and control birds; (2) $\Phi$ differed between sampled and control birds. LRT tests the significance of different effects on the apparent survival and apparent sighting probabilities by contrasting pairs of nested models, one containing the effect of interest with one where it is omitted. We tested whether the global model provided an adequate description of the data using the goodness of fit, and the global model fits the data satisfactorily $\left(\chi^{2}=12.70, d f=10, P=0.241\right)$.

Fledging success and foraging behaviour data were analysed using SAS statistical software (SAS Institute, v. 9.2, Chicago, IL, USA). Specifically, we examined whether capture and blood sampling affected the time albatrosses spent foraging by using repeated ANOVA with 'capture/ blood sample' as a factor and 'time at sea' as the repeated measurements (question 1). Experience of reproduction was not considered for this analysis because we did not monitor the time spent foraging at sea for any inexperienced albatross. There was no indication that normality assumption was violated for this analysis. We compared fledging success between 'sampled' and 'control' nests by using a generalized linear model (GLM) with a binomial distribution and a logit link function (dependent variable: fledging success; independent variables: 'capture/blood sample', 'experience' and their interaction). Therefore, we were able to examine whether the sampling process (capture, restraint and blood sample) significantly reduced fledging success in black-browed albatrosses (question 2). Moreover, we also investigated whether inexperienced birds were more likely to be affected by this sampling process than experienced birds by including the 'experience' factor and the 'experience $\mathrm{x}$ capture/blood sample' interaction (question 4). 
Table 1 Model selection using Akaike's Information criterion (AICc) in order to determine the influence of the sampling process (capture, restraint and blood sampling) on return rate of black-browed albatrosses

\begin{tabular}{|c|c|c|c|c|c|}
\hline No & Models & $K$ & $\mathrm{AICc}$ & $\Delta \mathrm{AICc}$ & $w$ \\
\hline 1 & $\Phi_{2004-2005}(.) P_{2005}()$. & 12 & 1225.27 & 0.00 & 0.384 \\
\hline 2 & $\Phi_{2004-2005}(.) P_{2005}($ sampled $)$ & 13 & $1,225.47$ & 0.20 & 0.348 \\
\hline 3 & $\Phi_{2004-2005}($ sampled $) P_{2005}()$. & 13 & $1,227.23$ & 1.96 & 0.144 \\
\hline 4 & $\Phi_{2004-2005}($ sampled $) P_{2005}($ sampled $)$ & 14 & $1,227.53$ & 2.26 & 0.124 \\
\hline
\end{tabular}

$\Phi$ and $P$, respectively, denote apparent survival and sighting probabilities; '(sampled)' and '(.)', respectively, denote an effect or no effect of the sampling process on these probabilities. Because the sampling procedure (capture, restraint, blood sampling) was only performed in 2004, the model selection only tested for an effect of this procedure on the survival probability from 2004 to 2005 ( $\left.\Phi_{2004-2005}\right)$ and on the sighting probability in $2005\left(P_{2005}\right) . K$ and $w$ refer, respectively, to the number of parameters and the AICc weight of each model

\section{Results}

Apparent survival and sighting probabilities

Our model selection showed that the most parsimonious model is the model that did not include any effect of the capture/sampling process on the sighting probability and the apparent survival probability (Table 1). Estimates of the sighting probabilities and apparent survival probabilities from the selected model are similar and did not differ significantly between sampled birds and control birds (sighting probability, LRT test, $\chi^{2}=1.77, P=0.184$; apparent survival probability, LRT test, $\chi^{2}=0.11$, $P=0.741$; Fig. 2).

\section{Foraging behaviour}

Time at sea did not differ between experimental and control birds (repeated ANOVA, $F_{1,14}=0.42$, $P=0.841$; Fig. 1). Moreover, time at sea did not differ between the first and the second monitored foraging trip for both groups (repeated ANOVA, time: $F_{1,14}=0.11$, $P=0.741$, time $\mathrm{x}$ capture/blood sample', $F_{1,14}=0.01$, $P=0.916$; Fig. 3), demonstrating that sampled birds and controls spent the same time at sea before and after the sampling process.

\section{Fledging success}

Fledging success of sampled nests and control nests was similar (GLM, $F_{1,131}=0.43, P=0.514$; Fig. 2 ), and the 'capture/sample $\mathrm{x}$ experience' interaction was not significant (GLM, $\left.F_{1,131}=0.13, P=0.718\right)$, demonstrating that the capture/sample process had no significant effect on the breeding success of either inexperienced or experienced birds. However, there was a significant effect of the 'experience' factor on fledging success with inexperienced birds having a lower success than experienced birds (GLM, $F_{1,131}=4.29, P=0.040$; Fig. 4).
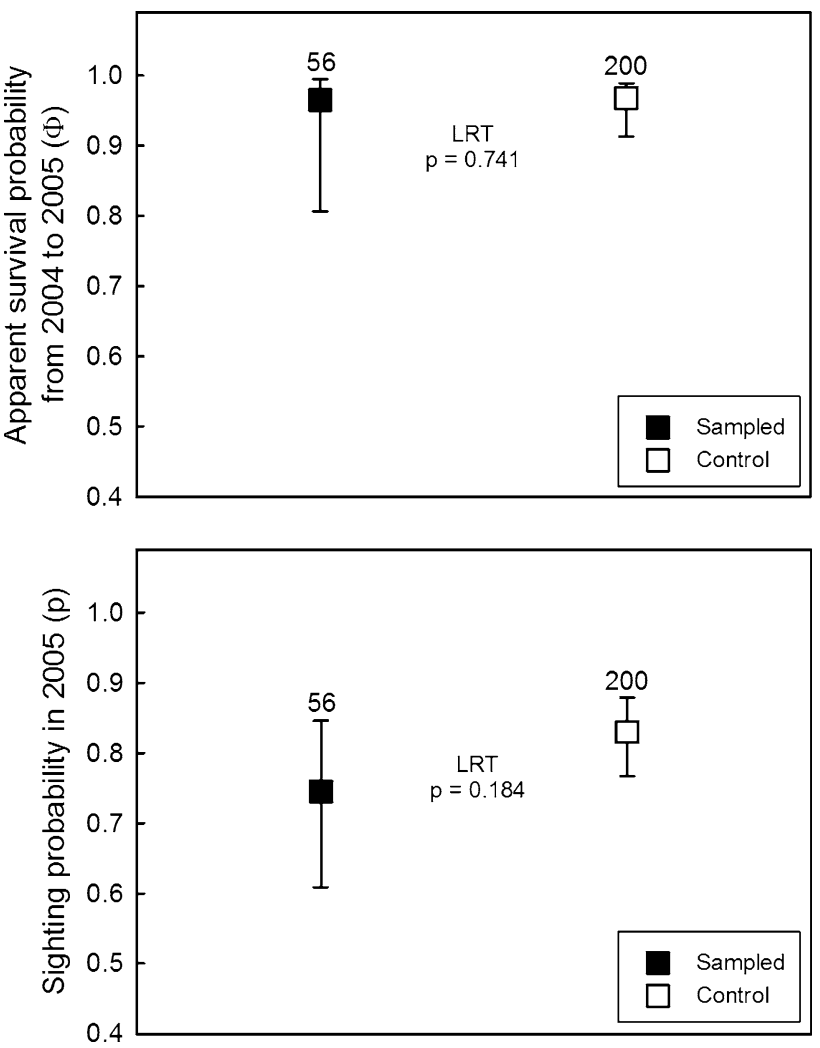

Fig. 2 Influence of the sampling process (capture, restraint and blood sampling) on return rate of black-browed albatrosses; Estimates of the apparent survival probability from 2004 to 2005 and the sighting probability in 2005 for sampled birds and controls showing 95\% confidence limits. Estimates were obtained from the general model (Model 4, Table 1). Likelihood ratio tests (LRT) were used to test whether these probabilities differed between sampled and control birds. Numbers above bars denote sample size for each group

\section{Discussion}

\section{Foraging behaviour}

We did not find any difference in the duration of foraging trip between sampled birds and controls (question 1). Moreover, we did not find any evidence that sampled birds 


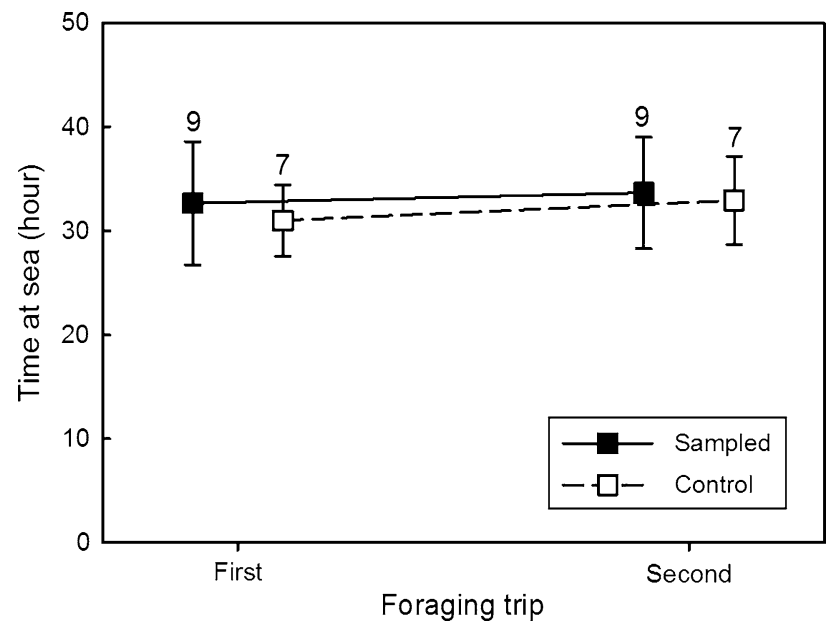

Fig. 3 Influence of the sampling process (capture, restraint and blood sampling) on the foraging behaviour of black-browed albatrosses; Time spent foraging at sea for sampled birds and controls (means \pm sem) during two subsequent foraging trips. The first trip occurred before the sampling process and the second trip occurred just after the sampling process. Numbers above bars denote sample size for each group

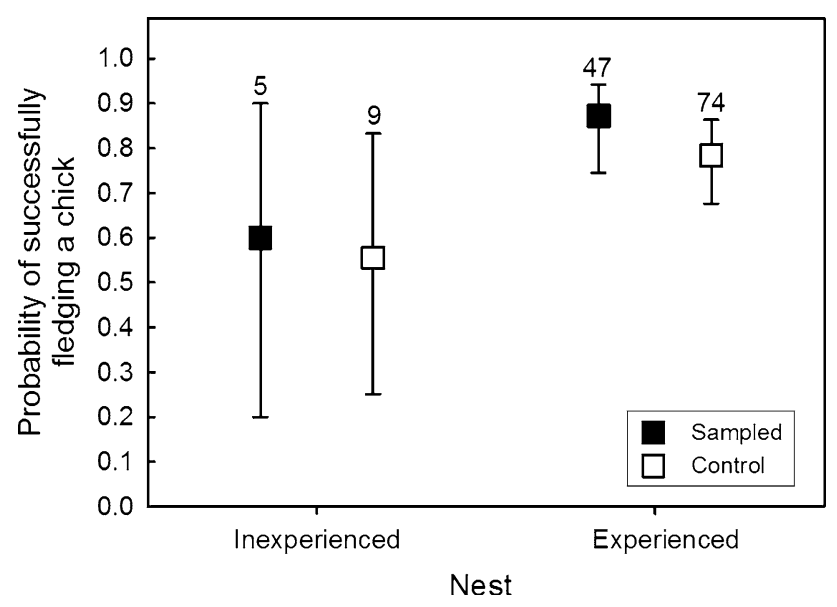

Fig. 4 Influence of the sampling process (capture, restraint and blood sampling) on the breeding success of black-browed albatrosses; Estimates of the probability of successfully fledging a chick for sampled birds and controls showing 95\% confidence limits. Estimates were obtained from the general model and are presented for inexperienced and experienced albatrosses. Numbers above bars denote sample size for each group

modified their foraging strategy after having been sampled. Therefore, our study shows that neither the tarsus vein puncture nor the capture and 5-min restraint induce a prolonged physical discomfort or a stress that affects the foraging decisions of an albatross parent during the brooding period. However, it has been reported that blackbrowed albatrosses can sometimes undertake longer foraging trips after having been captured, handled and equipped with a device (Phillips et al. 2003). In that respect, it is important to notice that the blood sampling process was performed quickly in our study $(\sim 5 \mathrm{~min})$, whereas device attachment usually requires more time ( $\sim 15 \mathrm{~min}$ ). This suggests that duration of handling time may play a role, with some birds being affected by the stress of handling and restraint when it exceeds a few minutes. However, the most likely reason for prolonged foraging in equipped birds is the additional load on the foraging bird (Brothers et al. 1998; Phillips et al. 2003).

\section{Reproductive performance}

We did not find any deleterious effect of our blood sampling protocol on fledging success of black-browed albatrosses (question 2). In seabirds, temporary or permanent nest desertion is the main handling-related cause of breeding failure (Ollason and Dunnet 1980; Brothers et al. 1998; Phillips et al. 2003; Blackmer et al. 2004). Definitive desertion by one of the parents induces almost automatically a breeding failure since the egg/chick cannot be sufficiently protected, incubated/brooded and fed by only one parent in procellariiforms. Temporary nest desertion often induces breeding failure in incubating or brooding black-browed albatrosses since the egg or the offspring is quickly predated by lesser sheathbills (Chionis minor) and brown skuas (Catharacta lonnbergi) when left alone. In addition, temporary nest desertion reduces the likelihood of an egg or a chick to hatch or fledge, respectively, because of cooling the egg and important metabolic costs for the chick (Olson et al. 2006). In our study, we captured and quickly blood sampled albatross parents when they had already been relieved from brooding duty by their mate. Thus, we limited the risk of breeding failure due to temporary desertion since the chick was protected and brooded by the other parent at the time of sampling. This specific protocol, in combination with the high tolerance of nesting albatrosses to disturbance (Wheeler et al. 2009), probably explains why we did not find any effect of our blood sampling protocol on fledging success. However, the result may be different during incubation, when birds are more prone to desert the nest (Rodway et al. 1996; Blackmer et al. 2004). Importantly, we did not find any effect of our protocol on fledging success of inexperienced birds (question 4), even though they are the most likely to desert their nest under poor environmental conditions (Angelier et al. 2007b; Nevoux et al. 2007).

\section{Return rate}

We did not report any significant effect of the blood sampling protocol on apparent survival of black-browed albatrosses, demonstrating that our sampling process did not have any impact on the ability of breeders to survive and to return to the monitored colony the following years 
(question 3). Unfortunately, we did not have enough statistical power to test an effect of the blood sampling protocol on apparent survival of inexperienced breeders because mortality is a rare event in black-browed albatrosses (Nevoux et al. 2007), and only a small percentage of birds in our study were inexperienced. However, all the inexperienced birds returned from their foraging trip to feed their chicks after the blood sampling protocol, confirming that this protocol did not carry any short-term survival cost. The absence of mortality due to the blood sampling protocol is not surprising since the volume of blood withdrawn was minimal $(0.5 \mathrm{ml}$ for a bird that weights $\sim 3,500 \mathrm{~g}$ ) and the handling time was short ( $\sim 5 \mathrm{~min}$ ). This result is in accordance with several studies that focused on foraging behaviour of black-browed albatrosses where capture, prolonged restraints $(>5 \mathrm{~min})$ and device attachments did not affect short-term or long-term survival (Pinaud and Weimerskirch 2002; Phillips et al. $2003,2004,2005)$. In addition, we did not detect any difference in the probability of seeing a bird breeding in the monitored colony during the subsequent breeding season between sampled and control birds. Therefore, our blood sampling protocol did not affect the likelihood of an albatross to skip breeding the following year or to emigrate temporarily from its breeding site (Blackmer et al. 2004).

\section{A complex effect of blood collection on seabird} performances

In seabirds, many factors can affect the way a species reacts to blood sampling. First, blood collection can be performed in different ways (brachial, tibiotarsus, jugular vein or directly from the heart), which may result in different levels of discomfort and stress and, thus, fitness consequences for individuals. For instance, the physical discomfort associated with the collection of blood from the brachial vein may contribute towards flight difficulties and the collection of blood from the large jugular vein may weaken a bird in the case of haematomas. Importantly, the discomfort may not have the same consequences depending on the biology of the species. Thus, collection of blood from the brachial vein may result in high costs in species that are highly dependent on their flight abilities such as swallows (Brown and Brown 2009), but only minor, insignificant costs in others (Sheldon et al. 2008). Second, the duration of the restraint may vary depending on the technique used, the experience of the researchers and the ease with which a species can be handled. This is important because handling duration may influence the degree to which a bird is stressed by the blood sampling protocol and, thus, affect its decision to continue or reduce its parental effort (Wingfield and Sapolsky 2003; Angelier and Chastel 2009). Third, blood collection can be performed during various life-history stages and under different environmental situations with contrasting effects on individuals. For example, black-browed albatrosses, as with most seabirds, are usually more prone to desert their nest when disturbed during either the early incubation or the late post-guarding stage (Phillips et al. 2003). Last but not least, seabird species can react differently to a blood sampling protocol. For instance, several seabird species are sensitive to disturbance and abandon reproduction in response to handling (e.g., atlantic puffins: Rodway et al. 1996; northern fulmars: Ollason and Dunnet 1980; Falk and Møller 1995; shy albatrosses: Brothers et al. 1998; leach's storm petrels: Blackmer et al. 2004), whereas others can be handled or blood sampled without any significant consequence to their fitness (ring-billed gulls: Brown 1995; southern fulmars: Van den Bring and Pigott 1996; albatross species: Phillips et al. 2003). Importantly, closely related species or even different populations of the same species can show contrasting responses to a blood sampling protocol. For instance, in contrast to black-browed albatrosses, shy albatrosses often abandon their nest when captured and handled (Brothers et al. 1998; Phillips et al. 2003; this study).

For all these reasons, it is difficult to predict without preliminary data how seabirds may be affected by a blood sampling protocol. Therefore, we recommend that ecophysiologists conduct pilot studies to test whether their blood sampling process may be used without affecting the survival, or breeding or foraging performances of their seabird population.

Acknowledgments The present research project No. 109 was performed at Kerguelen Station and was supported by the French Polar Institute (IPEV). This work was carried out during the tenure of Marie-Curie fellowship by F. Angelier (Polarclimstress project, IOF grant to F. Angelier). We are indebted to F. Le Bouard and D. Hyrenbach for their assistance in the field. We thank S.R. Sult and L. Denonfoux who improved the English of the manuscript and provided us with nice pictures of the study site respectively.

Open Access This article is distributed under the terms of the Creative Commons Attribution Noncommercial License which permits any noncommercial use, distribution, and reproduction in any medium, provided the original author(s) and source are credited.

\section{References}

Angelier F, Chastel O (2009) Stress, prolactin and parental investment in birds: a review. Gen Comp Endocrinol 163:142-148

Angelier F, Weimerskirch H, Dano S, Chastel O (2007a) Age, experience and reproductive performance in a long-lived bird: a hormonal perspective. Behav Ecol Sociobiol 61:611-621

Angelier F, Moe B, Weimerskirch H, Chastel O (2007b) Age-specific reproductive success in a long-lived bird: do older parents resist stress better? J Anim Ecol 76:1181-1191 
Angelier F, Wingfield JC, Weimerskirch H, Chastel O (2010) Hormonal correlates of individual quality in a long-lived bird: a test of the 'corticosterone-fitness hypothesis'. Biol Lett (in press)

Bize P, Criscuolo F, Metcalfe NB, Nasir L, Monaghan P (2009) Telomere dynamics rather than age predicts life expectancy in the wild. Proc R Soc B 276:1679-1683

Blackmer AL, Ackerman JT, Nevitt GA (2004) Effects of investigator disturbance on hatching success and nest-site fidelity in a longlived seabird, Leach's storm-petrel. Biol Cons 116:141-148

Brothers N, Gales R, Hedd A, Robertson G (1998) Foraging movements of the Shy albatross Diomedea cauta breeding in Australia; implications for interactions with longline fisheries. Ibis 140:446-457

Brown KM (1995) Does blood sampling Ring-billed gulls increase parental desertion and chick mortality? Col Waterbirds 18:102-104

Brown MB, Brown CR (2009) Blood sampling reduces survival in cliff swallows (Petrochelidon pyrrhonota). Auk 126:853-861

Burnham KP, Anderson DR (2002) Model selection and multimodel inference. Springer, New York

Chastel O, Lacroix A, Weimerskirch H, Gabrielsen GW (2005) Modulation of prolactin but not corticosterone responses to stress in relation to parental effort in a long-lived bird. Horm Behav 47:459-466

Cherel Y, Hobson KA, Weimerskirch H (2005) Using stable isotopes to study resource acquisition and allocation in procellariiform seabirds. Oecologia 145:533-540

Colwell MA, Gratto CL, Oring LW, Pizzant AJ (1988) Effects of blood sampling on shorebirds: injuries, return rates and clutch desertions. Condor 90:942-945

Criscuolo F (2001) Does blood sampling during incubation induce nest desertion in the female Common eider (Somateria mollissima)? Mar Ornithol 29:47-50

Criscuolo F, Chastel O, Gabrielsen GW, Lacroix A, Le Maho Y (2002) Factors affecting plasma concentrations of prolactin in the common eider Somateria mollissima. Gen Comp Endocrinol 125:399-409

De Villiers M, Bause M, Giese M, Fourie A (2006) Hardly hardhearted: heart rate responses of incubating Northern Giant Petrels (Macronectes halli) to human disturbance on subAntarctic Marion island. Pol Biol 29:717-720

Drent RH, Daan S (1980) The prudent parent: energetic adjustments in avian breeding. Ardea 68:225-252

Dufty AM (1988) The effects of repeated blood sampling on survival of Brown-headed cowbirds. Condor 90:939-941

Falk K, Møller S (1995) Satellite tracking of high-arctic northern fulmars. Pol Biol 15:495-502

Fridolfsson AK, Ellegren H (1999) A simple and universal method for molecular sexing of non-ratite birds. J Avian Biol 30:116-121

Gaunt AS, Oring LW, Able KP, Anderson DW, Baptista LF, Barlow JC, Wingfield JC (eds) (1997) Guidelines to the use of wild birds in research. The Ornithological Council, Washington, DC, USA

Hall M, Nasir L, Daunt F, Gault E, Croxall J, Wanless S, Monaghan P (2004) Telomere loss in relation to age and early environment in long-lived birds. Proc R Soc B 271:1571-1576

Heidinger BJ, Nisbet ICT, Ketterson E (2006) Older parents are less responsive to a stressor in a long-lived seabird: a mechanism for increased reproductive performance with age? Proc R Soc B 273: 2227-2231

Hoysak DJ, Weatherhead PJ (1991) Blood sampling from birds: a technique and assessment of its effect. Condor 93:746-752

Kania W (1992) Safety of catching adult European birds at the nest. Ring Opin Ring 14:5-50

Kitaysky AS, Wingfield JC, Piatt JF (1999) Dynamics of food availability, body condition and physiological response in breeding Black-legged kittiwakes. Funct Ecol 13:577-585
Lanctot RB (1994) Blood sampling in juvenile buff-breasted sandpipers: movement, mass change and survival. J Field Ornithol 65:534-542

Landys MM, Piersma T, Guglielmo CG, Jukema J, Ramenofsky M, Wingfield JC (2005) Metabolic profile of long-distance migratory flight and stopover in a shorebird. Proc R Soc B 272:295302

Lubjuhn T, Brun J, Winkel W, Muth S (1998) Effects of blood sampling in great tits. J Field Ornithol 69:595-602

Nevoux M, Weimerskirch H, Barbraud C (2007) Environmental variation and experience-related differences in the demography of the long-lived black-browed albatross. J Anim Ecol 76:159167

Ollason JC, Dunnet GM (1980) Nest failures in the fulmar: the effect of observers. J Field Ornithol 51:39-54

Olson CR, Vleck CM, Vleck D (2006) Periodic cooling of bird eggs reduces embryonic growth efficiency. Physiol Biochem Zool 79:927-936

Oring LW, Able KP, Anderson DW, Baptista LF, Barlow JC, Gaunt AS, Gill FB, Wingfield JC (1988) Guidelines for use of wild birds in research. Auk 105:23a-24a

Palacios MG, Cunnick JE, Winkler DW, Vleck CM (2007) Immunosenescence in some but not all immune components in a freeliving vertebrate, the tree swallow. Proc R Soc B 274:951-957

Perkins KA, Roth RR, Bowman JL, Gree J, Brittingham M (2004) Flushing, capture, and bleeding do not affect return rate of female wood thrushes (Hylocichla mustelina) in Delaware. Auk 121:354-360

Phillips RA, Xavier JC, Croxall JP (2003) Effects of satellite transmitters on albatrosses and petrels. Auk 120:1082-1090

Phillips RA, Silk JRD, Phalan B, Catry P, Croxall JP (2004) Seasonal sexual segregation in two Thalassarche albatross species: competitive exclusion, reproductive role specialization or trophic niche divergence? Proc R Soc B 271:1283-1291

Phillips RA, Silk JRD, Croxall JP, Afanasyev V, Bennett VJ (2005) Summer distribution and migration of nonbreeding albatrosses: individual consistencies and implications for conservation. Ecology 86:2386-2396

Pinaud D, Weimerskirch H (2002) Ultimate and proximate factors affecting the breeding performance of a marine top-predator. Oikos 99:141-150

Ricklefs RE, Wikelski M (2002) The physiology/life-history nexus. Trends Ecol Evol 17:462-468

Rodway MS, Montevecchi WA, Chardine JW (1996) Effects of investigator disturbance on breeding success of Atlantic puffins Fratercula arctica. Biol Cons 76:311-319

Rolland V, Barbraud C, Weimerskirch H (2008) Combined effects of fisheries and climate on a migratory long-lived predator. J App Ecol 45:4-13

Schmoll T, Dietrich V, Winkel W, Lubjuhn T (2004) Blood sampling does not affect fledging success and fledgling local recruitment in coal tits (Parus ater). J Ornithol 145:79-80

Schmoll T, Schurr FM, Winkel W, Epplen JT, Lubjuhn T (2009) Lifespan, lifetime reproductive performance and paternity loss of within-pair and extra-pair offspring in the coal tit Periparus ater. Proc R Soc B 276:337-345

Sheldon LD, Chin EH, Gill SA, Schmaltz G, Newman AEM, Soma KK (2008) Effects of blood collection on wild birds: an update. Auk 39:369-378

Van den Brink NW, Pigott K (1996) Effects of sampling blood and uropygial oil on breeding success of Antarctic birds. J Field Ornithol 67:623-629

Wada H, Cristol DA, McNabb FMA, Hopkins WA (2009) Suppressed adrenocortical responses and thyroid hormone levels in birds near a mercury-contaminated river. Env Sci Technol 43:60316038 
Weimerskirch H (1999) The role of body condition on breeding and foraging decisions in albatrosses and petrels. In: Proceedings of the 22nd international ornithological congress, BirdLife, Durban, South Africa

Weimerskirch H, Shaffer SA, Mabille G, Martin J, Boutard O, Rouanet JL (2002) Heart rate and energy expenditure of incubating wandering albatrosses: basal levels, natural variation, and the effects of human disturbance. J Exp Biol 205:475-483

Wheeler M, De Villiers MS, Majiedt PA (2009) The effect of frequency and nature of pedestrian approaches on the behaviour of albatrosses at sub-Antarctic Marion Island. Pol Biol 32:297-305
White GC, Burnham KP (1999) Program MARK: survival rate estimation from both live and dead encounters. Bird Study 46:S120-S139

Wingfield JC, Farner DS (1976) Avian endocrinology—-field investigations and methods. Condor 78:570-573

Wingfield JC, Sapolsky RM (2003) Reproduction and resistance to stress: when and how? J Neuroendocrinol 15:711-724

Wingfield JC, Visser M, Williams TD (2008) Introduction. Integration of ecology and endocrinology in avian reproduction: a new synthesis. Phil Trans R Soc B 363:1581-1588

Zera AJ, Harshman LG (2001) The physiology of life-history tradeoffs in animals. Ann Rev Ecol Evol Syst 32:95-126 